\title{
Association between serum 25-hydroxyvitamin D, hemoglobin A1c and fasting blood glucose levels in adults with diabetes mellitus
}

\author{
MOHAMMAD J. ALKHATATBEH and KHALID K. ABDUL-RAZZAK
}

Department of Clinical Pharmacy, Faculty of Pharmacy, Jordan University of Science and Technology, Irbid 22110, Jordan

Received August 24, 2018; Accepted October 16, 2018

DOI: $10.3892 / b r .2018 .1159$

\begin{abstract}
In the present study, the aim was to investigate the association between serum 25-hydroxyvitamin D concentration and measures of glycemic control including hemoglobin A1c (HbA1c) and fasting blood glucose (FBG) in adult patients with diabetes mellitus (DM) from the north of Jordan. Another aim was to compare serum levels of 25-hydroxyvitamin D between patients with good glycemic control and patients with uncontrolled DM. This was a cross-sectional study that included 261 participants with DM. The concentration of 25-hydroxyvitamin D was measured using electrochemiluminescence immunoassay, HbAlc was measured using turbidimetric inhibition immunoassay andFBG was measured using the hexokinase method. Data regarding other clinical variables were obtained from medical records or by self-reporting. Participants with good glycemic control exhibited significantly higher levels of 25-hydroxyvitamin D compared with participants with uncontrolled $\mathrm{DM}(\mathrm{P}=0.03)$. Participants with sufficient vitamin D status $(>30 \mathrm{ng} / \mathrm{ml}$ in serum) exhibited significantly lower HbA1c level compared with participants with deficient vitamin $\mathrm{D}(<20 \mathrm{ng} / \mathrm{ml})$ status $(\mathrm{P}=0.02)$. Correlation analysis determined significant inverse correlations between 25-hydroxyvitamin $\mathrm{D}$ levels and $\mathrm{HbA1c}$ and FBG levels ( $\mathrm{r}=-0.23$ and -0.17 , respectively, both $\mathrm{P}<0.01)$. There were also significant correlations between duration of DM and HbA1c and FBG levels (both $r=0.21$, $\mathrm{P}<0.01)$. HbA1c level was also inversely correlated with participants' age $(r=-0.19, \mathrm{P}<0.01)$. Further multiple linear regression analysis revealed an inverse significant association between HbA1c and 25-hydroxyvitamin D levels $(F=12.95$, $\left.\mathrm{R}^{2}=0.48, \mathrm{P}<0.01\right)$ but did not identify a similar association between FBG and 25-hydroxyvitamin D levels. These findings may encourage further research to identify if vitamin D
\end{abstract}

Correspondence to: Dr Mohammad J. Alkhatatbeh, Department of Clinical Pharmacy, Faculty of Pharmacy, Jordan University of Science and Technology, Amman-Ramtha Street, Irbid 22110, Jordan

E-mail:khatatbeh@just.edu.jo

Key words: vitamin D, diabetes mellitus, hemoglobin A1c, glycemic control supplementation may improve measures of glycemic control, and how vitamin D may affect glucose homeostasis in patients with DM.

\section{Introduction}

Diabetes mellitus (DM) is characterized by chronic hyperglycemia caused by impaired insulin secretion, peripheral insulin resistance, or both (1). To prevent long-term micro- and macro-vascular complications, patients with DM are required to maintain adequate glycemic control, which is routinely assessed by measuring hemoglobin Alc (HbAlc) and fasting blood glucose (FBG) levels (2). This therapeutic target can be achieved by adhering to appropriate dietary and lifestyle modifications and to the proper medications (3).

Although nutrition recommendations for patients with DM focus on the proportion of calories obtained from carbohydrate, fat and protein (4), there is increasing data suggesting that vitamin D supplementation may be associated with improved glycemic control (5-7). This was based on prior studies that determined significant inverse associations between serum vitamin D level and measures of glycemic control including both HbA1c and FBG levels (8-10). The involvement of vitamin $\mathrm{D}$ in glucose metabolism is considered be associated with its role in pancreatic insulin secretion and peripheral insulin resistance (11). Despite being classified as a vitamin, vitamin $\mathrm{D}$ has also been noted to serve several hormonal functions that are proposed to result from its action on vitamin $\mathrm{D}$ receptors (VDRs), which are widely expressed on various cell types (12). Among these functions is the action of vitamin D on the VDRs of pancreatic beta islet cells (12). In animal studies, mice lacking functional VDRs exhibited impaired insulin secretion (13); furthermore, vitamin D supplementation was able to induce insulin biosynthesis in the pancreatic islets of rats (14). In humans, certain VDR gene variants have been associated with impaired insulin secretion and the development of type 2 DM (15). In addition, vitamin D may serve a role in peripheral insulin sensitivity through its action on VDRs expressed on human skeletal muscle and adipose tissue cells $(11,16,17)$. These cells are involved in determining peripheral insulin sensitivity as they are responsible for glucose uptake in response to insulin secretion (11).

Despite reports of a possible role for vitamin D in DM $(5,8,9)$, to our knowledge the present study is the first to investigate the association between serum vitamin $\mathrm{D}, \mathrm{HbAlc}$ 
and FBG levels in adults with DM from northern Jordan. The aim was to compare serum levels of 25-hydroxyvitamin D between DM patients with good glycemic control and patients with uncontrolled DM. Additionally, it was investigated whether associations existed between measures of glycemic control and other variables including age, duration of DM and medications.

\section{Materials and methods}

Study design. The current study was a cross-sectional study that involved 261 male and female adults (aged 19-79 years old; 111 men and 150 women) with type 1 or type 2 DM. This represented a response rate of $87 \%$ following assessment of eligibility. Patients were recruited from the outpatient diabetes clinic of King Abdullah University Hospital, Ramtha, Jordan between December 2016 and January 2018. Patients with chronic renal failure, chronic liver disease and/or on vitamin D supplementation for the past 3 months were excluded from the study. All participants were taking medications for the treatment of DM and its complications. Participants had been informed of the purpose of the study prior to signing consent forms. The study procedure was ethically approved by the Institutional Research Board of Jordan University of Science and Technology and King Abdullah University Hospital (Irbid, Jordan; approval no. 1092015).

Sample size calculation. Sample size was calculated based on the reported prevalence of vitamin D deficiency and insufficiency among patients with DM in northern Jordan, which was $87.1 \%$ as determined in our previous study (18). Sample size was determined using the formula [sample size $=$ $\left.(t)^{2}(p)(q) /(d)^{2}\right](19)$, where $t-v a l u e(t=1.96)$ represents the $95 \%$ confidence interval, $\mathrm{p}=0.87$ [the estimated prevalence of vitamin D deficiency and insufficiency (18)], q=1-p and d=0.05 (the margin of error based on the $95 \%$ confidence interval). Consequently, the calculated sample size was 173 patients. The current study included a larger number of patients with DM to increase reliability of results.

Data collection. Descriptive information regarding age, sex, type of DM, duration of DM, smoking status, history of chronic renal failure, history of chronic liver disease, history of previous supplementation of vitamin D and list of current medications were obtained from patients' medical records and/or by self-reporting. Body weight $(\mathrm{kg})$ was measured using a calibrated balance with wearing of light clothes and without shoes. Height $(\mathrm{cm})$ and waist circumference $(\mathrm{cm})$ were measured using a metric scale tape and body mass index (BMI) was calculated by dividing weight $(\mathrm{kg})$ by height squared $\left(\mathrm{m}^{2}\right)$. Systolic and diastolic blood pressures (SBP and DBP) were measured using a mercury sphygmomanometer by a registered nurse.

Blood processing and laboratory assays. Following overnight fasting, 10-ml venous blood samples were collected by a qualified laboratory technician to determine 25-hydroxyvitamin D, HbAlc and FBG levels. Serum was prepared within $2 \mathrm{~h}$ of blood collection by centrifuging blood samples at 2,100 x g for 8 min using a high-speed Jouan MR23i centrifuge
(Thermo Fisher Scientific, Inc., Waltham, MA, USA), with maintenance and preparation all at room temperature. FBG concentration was determined by the hexokinase method (20) using a Hitachi 902 auto-analyzer (Roche Diagnostics GmbH, Mannheim, Germany). The level of HbA1c was determined by turbidimetric inhibition immunoassay (21) using a cobas b 101 system (Roche Diagnostics GmbH). According to a recent report from the American College of Physicians that recommended a target $\mathrm{HbA1c}$ of $7-8 \%$ for adults with DM (2), participants with HbA1c $<8 \%$ were considered as having good glycemic control while participants with $\mathrm{HbA} 1 \mathrm{c} \geq 8 \%$ were considered as having uncontrolled DM. Serum 25-hydroxyvitamin D concentration was determined by electrochemiluminescence immunoassay (22) using a Roche Modular E170 Analyzer (Roche Diagnostics GmbH). Participants with serum 25-hydroxyvitamin D >30 ng/ml were considered as having sufficient vitamin D levels whereas participants with serum 25-hydroxyvitamin D of 20-30 ng/ml or less than $20 \mathrm{ng} / \mathrm{ml}$ were considered as having insufficient or deficient vitamin D levels, respectively (23).

Statistical analysis. The IBM SPSS statistics 20.0 software (IBM Corp., Armonk, New York, USA) was used to perform statistical analysis. All non-normally distributed continuous variables were log-transformed prior to analysis. Continuous variables were presented as mean \pm standard deviation or median (interquartile range). Qualitative variables were presented as number (percentage). Differences in the mean levels of continuous variables between participants with good glycemic control and participants with uncontrolled DM were determined by Student's t-test. Differences in qualitative variables between participants with good glycemic control and participants with uncontrolled DM were determined by $\chi^{2}$ test. Differences in the mean level of 25-hydroxyvitamin $\mathrm{D}$ between participants with deficient, insufficient and sufficient vitamin D levels were determined using one-way analysis of variance with Tukey's post hoc test for multiple comparisons. Correlation analyses between $\mathrm{HbA1c}, \mathrm{FBG}$ and other continuous variables were performed using the Pearson product-moment correlation test. Multiple linear regression analysis was used to detect independent predictors of HbAlc and FBG. All P-values were two-sided and considered statistically significant at $<0.05$.

\section{Results}

Characteristics of participants. The mean age of the patients was $54.94 \pm 10.92$ years. The mean duration of DM was $7.84 \pm 6.58$ years, the mean BMI was $30.77 \pm 4.80 \mathrm{~kg} / \mathrm{m}^{2}$, the mean waist circumference was $103.68 \pm 12.91 \mathrm{~cm}$, the mean SBP was $137.02 \pm 17.05 \mathrm{mmHg}$ and the mean DBP was $82.65 \pm 10.51 \mathrm{mmHg}$. The median fasting blood glucose (FBG) was $8.60(6.60-12.53) \mathrm{mmol} / \mathrm{l}$, the median HbA1c was $8.00(6.88-9.83) \%$ and the median serum 25-hydroxyvitamin D concentration was $14.80(8.42-22.67) \mathrm{ng} / \mathrm{ml}$. A total of $52(19.9 \%)$ participants were current smokers and $209(80.1 \%)$ participants were non-smokers. A total of $204(78.2 \%)$ participants were on insulin therapy, 238 (91.2\%) participants were on metformin therapy, 96 (36.8\%) participants were on sulfonylureas therapy, $98(37.5 \%)$ participants were on aspirin therapy, $123(47.1 \%)$ participants were on statins 
Table I. Characteristics of participants according to level of glycemic control.

\begin{tabular}{|c|c|c|c|}
\hline Characteristics & $\begin{array}{l}\text { Good glycemic control, } \\
\text { HbA1c }<8 \%(n=129)\end{array}$ & $\begin{array}{l}\text { Glycemic uncontrolled, } \\
\text { HbA1c } \geq 8 \%(n=132)\end{array}$ & P-value ${ }^{a}$ \\
\hline Age, years & $56.72 \pm 9.86$ & $53.19 \pm 11.64$ & $<0.01$ \\
\hline Sex & & & $<0.01$ \\
\hline Male & $43(33.3)$ & $68(51.5)$ & \\
\hline Female & $86(66.7)$ & $64(48.5)$ & \\
\hline Smoking & $21(16.3)$ & $31(23.5)$ & 0.16 \\
\hline Height, cm & $165.28 \pm 9.07$ & $167.07 \pm 10.19$ & 0.14 \\
\hline Weight, kg & $85.43 \pm 13.00$ & $84.33 \pm 15.30$ & 0.53 \\
\hline $\mathrm{BMI}, \mathrm{kg} / \mathrm{m}^{2}$ & $31.16 \pm 4.12$ & $30.38 \pm 5.37$ & 0.19 \\
\hline $\mathrm{WC}, \mathrm{cm}$ & $104.18 \pm 11.93$ & $103.20 \pm 13.82$ & 0.55 \\
\hline $\mathrm{DM}$ & & & $<0.01$ \\
\hline Type 1 & $2(1.6)$ & $20(15.2)$ & \\
\hline Type 2 & $127(98.4)$ & $112(84.8)$ & \\
\hline Log [duration of DM (months)] & $1.67 \pm 0.49$ & $1.87 \pm 0.51$ & $<0.01$ \\
\hline $\log [\mathrm{FBG}(\mathrm{mmol} / \mathrm{l})]$ & $0.87 \pm 0.14$ & $1.06 \pm 0.19$ & $<0.01$ \\
\hline $\log [\mathrm{HbA} 1 \mathrm{c}(\%)]$ & $0.83 \pm 0.06$ & $1.00 \pm 0.07$ & $<0.01$ \\
\hline $\mathrm{SBP}, \mathrm{mmHg}$ & $136.58 \pm 16.08$ & $137.45 \pm 18.01$ & 0.68 \\
\hline $\mathrm{DBP}, \mathrm{mmHg}$ & $83.61 \pm 9.22$ & $81.70 \pm 11.60$ & 0.15 \\
\hline Insulin & $100(77.5)$ & $104(78.8)$ & 0.80 \\
\hline Metformin & $124(96.1)$ & $114(86.4)$ & $<0.01$ \\
\hline Sulfonylureas & $44(34.1)$ & $52(39.4)$ & 0.38 \\
\hline Aspirin & $53(41.1)$ & $45(34.1)$ & 0.24 \\
\hline Statins & $65(50.4)$ & $58(43.9)$ & 0.30 \\
\hline Beta blockers & $19(14.7)$ & $20(15.2)$ & 0.92 \\
\hline ACEIs & $39(30.2)$ & $40(30.3)$ & 0.99 \\
\hline $\mathrm{CCBs}$ & $18(14.0)$ & $14(10.6)$ & 0.41 \\
\hline PPIs & $20(15.5)$ & $25(18.9)$ & 0.46 \\
\hline Log [25-hydroxyvitamin D (ng/ml)] & $1.18 \pm 0.26$ & $1.10 \pm 0.30$ & 0.03 \\
\hline
\end{tabular}

therapy, 39 (14.9\%) participants were on beta blockers therapy, $79(30.3 \%)$ participants were on angiotensin converting enzyme inhibitors therapy, $32(12.3 \%)$ participants were on calcium channel blockers therapy and 45 (17.2\%) participants were on proton pump inhibitors therapy. Descriptive characteristics of the participants according to their glycemic control are presented in Table I.

Correlation of $\mathrm{HbAlc}$ and FBG with serum 25-hydroxyvitamin $D$ and other variables. As shown in Table I, serum 25-hydroxyvitamin D was significantly higher in participants with controlled DM compared with in those with uncontrolled DM $(\mathrm{P}=0.03)$. HbA1c level was significantly higher in participants with deficient $(<20 \mathrm{ng} / \mathrm{ml})$ vitamin D level compared with in participants with sufficient (>30 ng/ml) vitamin D level $(\mathrm{P}=0.02$; Fig. 1A). Whereas, there was no significant difference in HbA1c level between participants with deficient or sufficient and insufficient vitamin D levels ( $\mathrm{P}>0.05$; Fig. 1A). In addition, there was no significant difference in FBG level between participants with sufficient, insufficient and deficient vitamin D levels (Fig. 1A). Further correlation analyses (Table II) between HbAlc, FBG, serum 25-hydroxyvitamin D and other variables determined significant inverse correlations between serum 25-hydroxyvitamin D and HbA1c $(r=-0.23, \mathrm{P}<0.01)$ and between serum 25-hydroxyvitamin D and FBG ( $r=-0.17$, $\mathrm{P}<0.01$; Fig. 1B). HbA1c was also inversely correlated with participant's age $(r=-0.19, \mathrm{P}<0.01)$ and directly correlated with duration of DM $(r=0.21, \mathrm{P}<0.01)$ and FBG $(r=0.61, \mathrm{P}<0.01)$. FBG was also directly correlated with duration of DM $(r=0.21$, $\mathrm{P}<0.01)$.

Association of HbAlc and FBG with serum 25-hydroxyvitamin $D$ and other variables. Multiple linear regression analyses were performed to identify the potential predictors of HbA1c and FBG levels (Table III). HbA1c was 
Table II. Correlation of HbA1c and FBG with other variables.

\begin{tabular}{|c|c|c|c|c|}
\hline \multirow[b]{2}{*}{ Characteristics } & \multicolumn{2}{|c|}{$\log [\mathrm{HbA} 1 \mathrm{c}(\%)]$} & \multicolumn{2}{|c|}{$\log [\mathrm{FBG}(\mathrm{mmol} / \mathrm{l})]$} \\
\hline & $\mathrm{r}$ & P-value ${ }^{a}$ & $\mathrm{r}$ & P-value \\
\hline Age & -0.19 & $<0.01$ & -0.12 & 0.06 \\
\hline Height, $\mathrm{cm}$ & 0.04 & 0.50 & -0.05 & 0.45 \\
\hline Weight, kg & -0.08 & 0.21 & 0.02 & 0.75 \\
\hline BMI, $\mathrm{kg} / \mathrm{m}^{2}$ & -0.08 & 0.21 & 0.05 & 0.42 \\
\hline $\mathrm{WC}, \mathrm{cm}$ & -0.03 & 0.63 & 0.11 & 0.10 \\
\hline Log [duration of DM (months)] & 0.21 & $<0.01$ & 0.21 & $<0.01$ \\
\hline $\log [\mathrm{FBG}(\mathrm{mmol} / \mathrm{l})]$ & 0.61 & $<0.01$ & - & - \\
\hline $\mathrm{SBP}(\mathrm{mmHg})$ & 0.05 & 0.46 & 0.01 & 0.87 \\
\hline $\mathrm{DBP}(\mathrm{mmHg})$ & -0.10 & 0.12 & -0.07 & 0.25 \\
\hline Log [25-hydroxyvitamin D (ng/ml)] & -0.23 & $<0.01$ & -0.17 & $<0.01$ \\
\hline
\end{tabular}

${ }^{a}$ Pearson product-moment correlation test (P-values were two-tailed and considered statistically significant at $<0.05$ ). r, correlation coefficient; HbA1c, hemoglobin A1c; DM, diabetes mellitus; BMI, body mass index; WC, waist circumference; FBG, fasting blood glucose; SBP, systolic blood pressure; DBP, diastolic blood pressure.

A

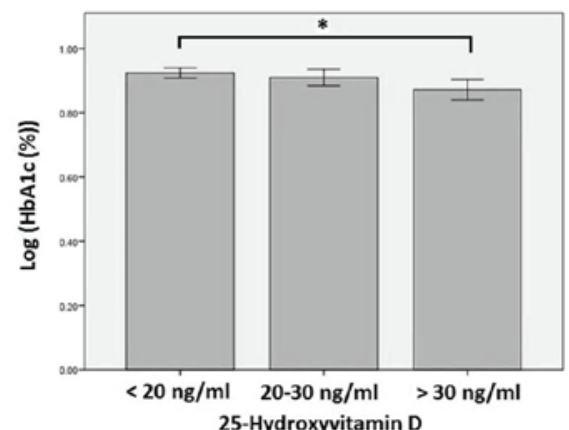

B

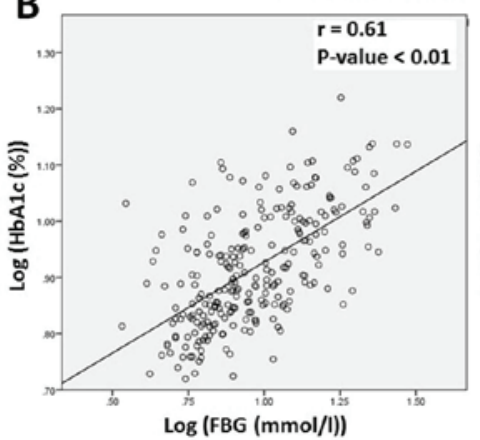

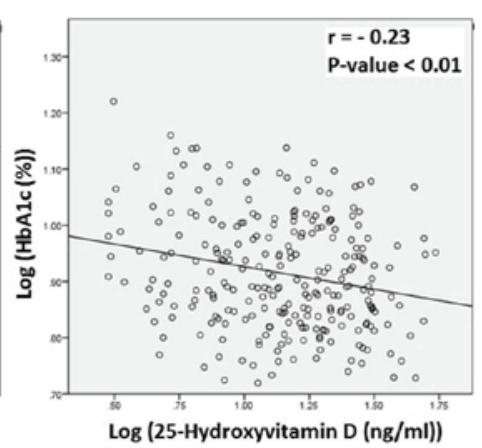

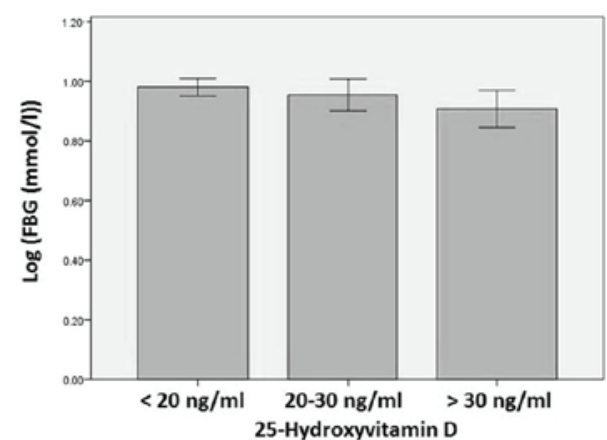

roxyvitamin D

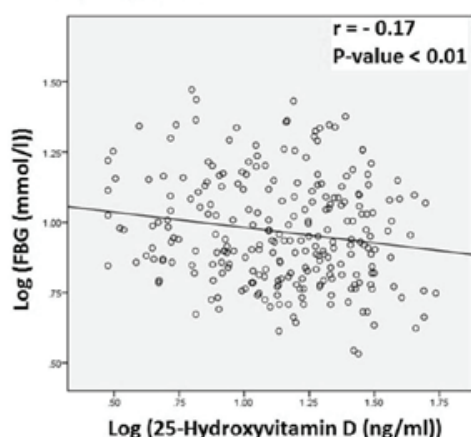

Figure 1. Association between serum 25-hydroxyvitamin D, HbA1c and FBG levels in adults with diabetes mellitus. (A) HbA1c and FBG levels in participants according to vitamin D status. HbAlc level in participants with sufficient vitamin D (>30 ng/ml) was significantly higher than the level in participants with deficient vitamin D $(<20 \mathrm{ng} / \mathrm{ml})$. There was no significant difference in HbAlc level between participants with insufficient vitamin D (20-30 ng/ml) and participants with either sufficient or deficient vitamin D. In addition, there was no significant difference in FBG level between participants with sufficient, insufficient or deficient vitamin D. Data is expressed as mean \pm standard deviation. (B) Significant correlation between HbA1c and FBG levels and significant inverse correlations between 25-hydroxyvitamin D and HbA1c and FBG levels. *P=0.02. HbA1c, hemoglobin A1c; FBG, fasting blood glucose.

inversely associated with serum 25-hydroxyvitamin D level and directly associated with FBG (both $\mathrm{P}<0.01)$. HbA1c was also associated with type of DM $(\mathrm{P}<0.01)$, indicating that participants with type $1 \mathrm{DM}$ had higher levels of HbA1c (Tables I and III). FBG was associated with statins therapy $(\mathrm{P}=0.04)$, indicating that participants on statin therapy had lower levels of FBG (Tables I and III).

\section{Discussion}

In the present descriptive study, the aim was to assess the association between serum 25-hydroxyvitamin D levels and measures of glycemic control in adults with DM from the north of Jordan. Patients with good glycemic control exhibited significantly higher levels of 25-hydroxyvitamin D compared 
Table III. Association of HbA1c and FBG with other variables.

\begin{tabular}{|c|c|c|c|c|c|c|c|}
\hline Dependent variable & $\mathrm{R}^{2}$ & ANOVA & Model & $\mathrm{B}$ & $\beta$ & t-value & P-value ${ }^{a}$ \\
\hline \multirow[t]{17}{*}{$\log [\mathrm{HbA} 1 \mathrm{c}(\%)]$} & 0.48 & $\begin{array}{l}F=12.95 \\
P<0.01\end{array}$ & Constant & 0.86 & - & 13.24 & $<0.01$ \\
\hline & & & Age & $<-0.01$ & -0.06 & -1.03 & 0.30 \\
\hline & & & $\begin{array}{l}\log \text { (duration } \\
\text { of DM) }\end{array}$ & 0.02 & 0.08 & 1.47 & 0.14 \\
\hline & & & $\begin{array}{l}\log [\mathrm{FBG} \\
(\mathrm{mmol} / \mathrm{l})]\end{array}$ & 0.29 & 0.54 & 10.53 & $<0.01$ \\
\hline & & & $\begin{array}{l}\text { Log [25-hydroxy- } \\
\text { vitamin D (ng/ml)] }\end{array}$ & -0.05 & -0.13 & -2.67 & $<0.01$ \\
\hline & & & Type of DM & -0.06 & -0.17 & -2.39 & 0.02 \\
\hline & & & Sex & -0.02 & -0.09 & -1.64 & 0.10 \\
\hline & & & Smoking & 0.01 & 0.03 & 0.56 & 0.57 \\
\hline & & & Metformin therapy & -0.03 & -0.07 & -1.17 & 0.24 \\
\hline & & & Sulfonylureas therapy & 0.01 & 0.03 & 0.56 & 0.58 \\
\hline & & & Insulin therapy & $<0.01$ & $<0.01$ & 0.15 & 0.88 \\
\hline & & & Statin therapy & $<0.01$ & 0.04 & 0.70 & 0.49 \\
\hline & & & Beta blocker therapy & 0.02 & 0.06 & 1.15 & 0.25 \\
\hline & & & ACEIs therapy & 0.02 & 0.07 & 1.18 & 0.24 \\
\hline & & & Aspirin therapy & -0.02 & -0.11 & -1.81 & 0.07 \\
\hline & & & CCBs therapy & $<-0.01$ & -0.01 & -0.27 & 0.79 \\
\hline & & & PPIs therapy & -0.01 & -0.05 & -1.06 & 0.29 \\
\hline \multirow[t]{16}{*}{$\log [\mathrm{FBG}(\mathrm{mmol} / \mathrm{l})]$} & 0.42 & $\begin{array}{l}F=11.00 \\
P<0.01\end{array}$ & Constant & -0.15 & - & -0.86 & 0.39 \\
\hline & & & $\begin{array}{l}\text { Log (duration of } \\
\text { DM) }\end{array}$ & 0.03 & 0.07 & 1.29 & 0.20 \\
\hline & & & $\log [\operatorname{HbA} 1 \mathrm{c}(\%)]$ & 1.14 & 0.61 & 10.69 & $<0.01$ \\
\hline & & & $\begin{array}{l}\text { Log [25-hydroxy- } \\
\text { vitamin D }(\mathrm{ng} / \mathrm{ml})]\end{array}$ & -0.02 & -0.04 & -0.68 & 0.50 \\
\hline & & & Type of DM & -0.02 & -0.03 & -0.41 & 0.68 \\
\hline & & & Sex & $<0.01$ & 0.02 & 0.27 & 0.79 \\
\hline & & & Smoking & $<0.01$ & $<0.01$ & 0.13 & 0.90 \\
\hline & & & Metformin therapy & 0.09 & 0.13 & 2.01 & 0.05 \\
\hline & & & Sulfonylureas therapy & 0.02 & 0.06 & 1.02 & 0.31 \\
\hline & & & Insulin therapy & -0.02 & -0.05 & -0.88 & 0.38 \\
\hline & & & Statins therapy & -0.05 & -0.12 & -2.02 & 0.04 \\
\hline & & & Beta blocker therapy & -0.01 & -0.02 & -0.33 & 0.74 \\
\hline & & & ACEIs therapy & -0.03 & -0.06 & -1.07 & 0.29 \\
\hline & & & Aspirin therapy & 0.04 & 0.11 & 1.75 & 0.08 \\
\hline & & & CCBs therapy & $<0.01$ & 0.01 & 0.24 & 0.81 \\
\hline & & & PPIs therapy & 0.03 & 0.06 & 1.03 & 0.30 \\
\hline
\end{tabular}

${ }^{a}$ Multiple linear regression analysis (P-values were considered statistically significant at $<0.05$ ). HbA1c, hemoglobin A1c; DM, diabetes mellitus; FBG, fasting blood glucose; ACEIs, angiotensin converting enzyme inhibitors; CCBs, calcium channel blockers; PPIs, proton pump inhibitors; R2, coefficient of determination; B, unstandardized coefficient; $\beta$, standardized coefficient; F, F-statistic; t, t-statistic.

with patients with uncontrolled DM. Additionally, patients with sufficient vitamin D status exhibited significantly lower HbA1c levels (but not FBG levels) compared with patients with deficient vitamin D status. Correlation analysis also revealed significant inverse correlations between 25-hydroxyvitamin D levels and HbA1c and FBG levels. Further multiple linear regression analysis identified an inverse significant association between HbA1c and 25-hydroxyvitamin D levels but did not find similar association between FBG and 25-hydroxyvitamin D levels.

These findings are comparable with those reported in previous similar studies. For instance, Zoppini et al (8) and Kostoglou-Athanassiou et al (10) observed a signifi- 
cant inverse association between 25-hydroxyvitamin D and HbA1c levels in patients with type $2 \mathrm{DM}$, though Zoppini et al (8) did not detect a significant correlation between 25-hydroxyvitamin D and FBG levels in their cohort. In addition, Lim et al (24) and Kajbaf et al (25) found a significant inverse association between 25-hydroxyvitamin D and HbA1c levels in type $2 \mathrm{DM}$ patients with chronic kidney disease. In patients with type 1 or $2 \mathrm{DM}$, Buhary et al (5) also detected a significant inverse association between HbA1c and 25-hydroxyvitamin D levels, and observed that supplementation of vitamin D was able to improve glycemic control by reducing HbA1c levels. Although this finding was supported by a recent systematic review and meta-analysis, which concluded that supplementation of vitamin D was associated with reduced HbAlc levels in patients with type 2 DM (7), other systematic reviews and meta-analyses $(26,27)$ have not supported the notion that vitamin D supplementation may improve measures of glycemic control including HbAlc levels. Thus, the association between vitamin D and HbA1c levels in patients with DM does not essentially imply the involvement of vitamin D supplementation in improving glycemic control. This exposes the question of whether the relationship between vitamin D deficiency and glucose homeostasis is causal or confounding (28).

However, the possible role of vitamin D in glucose metabolism may be due to its action on VDRs expressed on cells of the pancreatic beta islets (12), skeletal muscle and adipose tissue $(11,16,17)$. Vitamin D binding to these receptors may be involved in enhancing pancreatic insulin secretion and peripheral insulin sensitivity by increasing glucose uptake in skeletal muscle and adipose tissue (11). The inconsistent effect of vitamin D supplementation in improving glycemic control $(5,7,26,27)$ may be explained by the possible action of vitamin $\mathrm{D}$ on enhancing insulin secretion, which depends on the reserved function of the pancreatic beta islet cells (29). Patients with type 2 DM may have variable and progressive decrease in pancreatic insulin secretion (29). Therefore, the variability in responding to vitamin D supplementation could be due to the variability in the reserved beta islet cell function, which may differ from one patient to another. Consequently, it is possible that if patients have complete pancreatic beta cell dysfunction, vitamin D supplementation may not affect insulin secretion and thus glycemic control.

In the current study, 25-hydroxyvitamin D was inversely associated with HbA1c but not with FBG. This suggests that maintaining a sufficient vitamin D level in DM patients may improve HbA1c but not FBG. The difference between the two glycemic measures is that HbA1c reflects the average level of blood glucose over the past 2-3 months while FBG represents a single measurement of blood glucose concentration following overnight fasting (30). As FBG is determined by the level of basal insulin secretion and HbAlc by the level of both basal and postprandial insulin secretion (31), the present results suggest that the association between vitamin $\mathrm{D}$ and HbA1c could be due to vitamin D involvement in postprandial insulin secretion rather than basal insulin secretion. The effect of vitamin D on insulin secretion may also be indirect by increasing intracellular calcium (28). One of the principal functions of vitamin D is to increase calcium absorption from the gastrointestinal tract (32). In the postprandial situation, increased vitamin D-dependent calcium absorption may increase intracellular calcium, which could act as a mediator of postprandial insulin secretion (28) and thus improve HbA1c level without affecting FBG level.

Although participants with controlled DM were of significantly increased age, presented with shorter duration of DM, were of a greater female proportion and were using metformin more than participants with uncontrolled DM, multiple linear regression analysis did not reveal any significant association between these parameters and measures of glycemic control. Participants with type 2 DM more frequently had controlled DM compared with participants with type $1 \mathrm{DM}$. Consistently, regression analysis demonstrated a significant association between HbAlc level and DM type, which suggests that patients with type $1 \mathrm{DM}$ had higher levels of HbA1c compared with patients with type 2 DM. Interestingly, FBG level was significantly inversely associated with the use of statin therapy, suggesting that these medications may have a positive effect on FBG.

Collectively, the current study confirmed a significant inverse association between serum 25-hydroxyvitamin D and HbA1c levels but did not identify such association between 25-hydroxyvitamin D and FBG levels in adult patients with DM from northern Jordan. The current study had strength in its relatively large sample size, making the results comparable with findings reported in other similar studies. In addition, the impact of patients' medications on the association between 25-hydroxyvitamin D and glycemic control was taken in consideration by including these medications in the regression analysis. However, the cross-sectional design prevented investigation into why 25-hydroxyvitamin D level was associated with HbA1c. As such, this association requires further investigation to determine if vitamin $D$ supplementation may improve glycemic control in adults with DM from Jordan. If vitamin D supplementation was to improve glycemic control, then further research to determine the mechanism by which vitamin $\mathrm{D}$ affects glucose homeostasis would be warranted. Another limitation was the emphasis on detecting an association between serum 25-hydroxyvitamin D level and measures of glycemic control without investigating a possible association between serum 25-hydroxyvitamin D and DM complications, which are the most important factors affecting the prognosis of DM patients (33). However, this may encourage future studies into the potential relationship between serum vitamin D and individual DM complications such as eye lesions, vascular lesions and kidney disease.

In conclusion, the present study observed a significant inverse association between serum 25-hydroxyvitamin D and HbAlc levels in adult patients with DM. Serum 25-hydroxyvitamin D level in patients with good glycemic control was significantly higher than in patients with uncontrolled DM. These findings may enhance further research to identify if vitamin D supplementation can improve HbA1c level in patients with DM, and if vitamin D can affect glucose homeostasis in DM.

\section{Acknowledgements}

Not applicable. 


\section{Funding}

The current study was supported by the Deanship of Research at Jordan University of Science and Technology (grant no. 109/2015).

\section{Availability of data and materials}

The datasets used and/or analyzed during the current study are available from the corresponding author on reasonable request.

\section{Authors' contributions}

MJA was responsible for study design, patient recruitment, data collection, data analysis and manuscript writing. KKAR was responsible for data interpretation and manuscript editing. Both authors approved the final version of the manuscript to be published.

\section{Ethics approval and consent to participate}

The study procedure was ethically approved by the Institutional Research Board of Jordan University of Science and Technology and King Abdullah University Hospital (Irbid, Jordan; approval no. 1092015). All participants agreed to participate in this study by signed written informed consent.

\section{Patient consent for publication}

All participants provided written informed consent permitting publication of relevant data following anonymization of personal information.

\section{Competing interests}

The authors declare that they have no competing interests.

\section{References}

1. Ndisang JF, Vannacci A and Rastogi S: Insulin Resistance, Type 1 and Type 2 Diabetes, and Related Complications 2017. J Diabetes Res 2017: 1478294, 2017.

2. Qaseem A, Wilt TJ, Kansagara D, Horwitch C, Barry MJ and Forciea MA; Clinical Guidelines Committee of the American College of Physicians: Hemoglobin A1c targets for glycemic control with pharmacologic therapy for nonpregnant adults with type 2 diabetes mellitus: A guidance statement update from the American college of physicians. Ann Intern Med 168: 569-576, 2018.

3. Sanghani NB, Parchwani DN, Palandurkar KM, Shah AM and Dhanani JV: Impact of lifestyle modification on glycemic control in patients with type 2 diabetes mellitus. Indian J Endocrinol Metab 17: 1030-1039, 2013.

4. Franz MJ, Boucher JL and Evert AB: Evidence-based diabetes nutrition therapy recommendations are effective: The key is individualization. Diabetes Metab Syndr Obes 7: 65-72, 2014.

5. Buhary BM, Almohareb O, Aljohani N, Alrajhi S, Elkaissi S, Sherbeeni S, Almaghamsi A, Khan SA and Almalki MH: Association of glycosylated hemoglobin levels with vitamin D status. J Clin Med Res 9: 1013-1018, 2017.

6. Lee CJ, Iyer G, Liu Y, Kalyani RR, Bamba N, Ligon CB, Varma S and Mathioudakis N: The effect of vitamin D supplementation on glucose metabolism in type 2 diabetes mellitus: A systematic review and meta-analysis of intervention studies. J Diabetes Complications 31: 1115-1126, 2017.
7. Wu C, Qiu S, Zhu X and Li L: Vitamin D supplementation and glycemic control in type 2 diabetes patients: A systematic review and meta-analysis. Metabolism 73: 67-76, 2017.

8. Zoppini G, Galletti A, Targher G, Brangani C, Pichiri I, Negri C, Stoico V, Cacciatori V and Bonora E: Glycated haemoglobin is inversely related to serum vitamin $\mathrm{D}$ levels in type 2 diabetic patients. PLoS One 8: e82733, 2013.

9. Haidari F, Zakerkish M, Karandish M, Saki A and Pooraziz S: Association between serum vitamin D level and glycemic and inflammatory markers in non-obese patients with type 2 diabetes. Iran J Med Sci 41: 367-373, 2016.

10. Kostoglou-Athanassiou I, Athanassiou P, Gkountouvas A and Kaldrymides P: Vitamin D and glycemic control in diabetes mellitus type 2. Ther Adv Endocrinol Metab 4: 122-128, 2013.

11. Alvarez JA and Ashraf A: Role of vitamin D in insulin secretion and insulin sensitivity for glucose homeostasis. Int J Endocrinol 2010: 351385, 2010.

12. Wang Y, Zhu J and DeLuca HF: Where is the vitamin D receptor? Arch Biochem Biophys 523: 123-133, 2012.

13. Zeitz U, Weber K, Soegiarto DW, Wolf E, Balling R and Erben RG: Impaired insulin secretory capacity in mice lacking a functional vitamin D receptor. FASEB J 17: 509-511, 2003.

14. Bourlon PM, Billaudel B and Faure-Dussert A: Influence of vitamin D3 deficiency and 1,25 dihydroxy vitamin D3 on de novo insulin biosynthesis in the islets of the rat endocrine pancreas. J Endocrinol 160: 87-95, 1999.

15. Sentinelli F, Bertoccini L, Barchetta I, Capoccia D, Incani M, Pani MG, Loche S, Angelico F, Arca M, Morini S, et al: The vitamin D receptor (VDR) gene rs11568820 variant is associated with type 2 diabetes and impaired insulin secretion in Italian adult subjects, and associates with increased cardio-metabolic risk in children. Nutr Metab Cardiovasc Dis 26: 407-413, 2016.

16. Simpson RU, Thomas GA and Arnold AJ: Identification of 1,25-dihydroxyvitamin D3 receptors and activities in muscle. J Biol Chem 260: 8882-8891, 1985.

17. Al-Shoumer KA and Al-Essa TM: Is there a relationship between vitamin D with insulin resistance and diabetes mellitus? World J Diabetes 6: 1057-1064, 2015.

18. Alkhatatbeh MJ, Abdul-Razzak KK, Khasawneh LQ and Saadeh NA: High prevalence of vitamin D deficiency and correlation of serum vitamin $\mathrm{D}$ with cardiovascular risk in patients with metabolic syndrome. Metab Syndr Relat Disord 15: 213-219, 2017.

19. Bartlett JE, Kotrlik JW and Higgins CC: Organizational research: Determining appropriate sample size in survey research. Inf Technol Learn Perform J 19: 43-50, 2001.

20. Schmidt FH: [Blood glucose levels in capilary blood of adults assessed by the hexokinase method (author's transl)]. Klin Wochenschr 51: 520-522, 1973 (In German)

21. Genc S, Omer B, Aycan-Ustyol E, Ince N, Bal F and Gurdol F: Evaluation of turbidimetric inhibition immunoassay (TINIA) and HPLC methods for glycated haemoglobin determination. J Clin Lab Anal 26: 481-485, 2012.

22. Leino A, Turpeinen U and Koskinen P: Automated measurement of 25-OH vitamin D3 on the Roche Modular E170 analyzer. Clin Chem 54: 2059-2062, 2008.

23. Holick MF: Vitamin D status: Measurement, interpretation, and clinical application. Ann Epidemiol 19: 73-78, 2009.

24. Lim LL, Ng YM, Kang PS and Lim SK: Association between serum 25-hydroxyvitamin D and glycated hemoglobin levels in type 2 diabetes patients with chronic kidney disease. J Diabetes Investig 9: 375-382, 2018

25. Kajbaf F, Mentaverri R, Diouf M, Fournier A, Kamel S and Lalau JD: The Association between 25-Hydroxyvitamin D and Hemoglobin A1c Levels in Patients with Type 2 Diabetes and Stage 1-5 Chronic Kidney Disease. Int J Endocrinol 2014: $142468,2014$.

26. George PS, Pearson ER and Witham MD: Effect of vitamin D supplementation on glycaemic control and insulin resistance: A systematic review and meta-analysis. Diabet Med 29: e142-e150, 2012.

27. Nigil Haroon N, Anton A, John J and Mittal M: Effect of vitamin D supplementation on glycemic control in patients with type 2 diabetes: A systematic review of interventional studies. J Diabetes Metab Disord 14: 3, 2015.

28. Lips P, Eekhoff M, van Schoor N, Oosterwerff M, de Jongh R Krul-Poel Y and Simsek S: Vitamin D and type 2 diabetes. J Steroid Biochem Mol Biol 173: 280-285, 2017.

29. Fonseca VA: Defining and characterizing the progression of type 2 diabetes. Diabetes Care 32 (Suppl 2): S151-S156, 2009. 
30. Sherwani SI, Khan HA, Ekhzaimy A, Masood A and Sakharkar MK: Significance of HbAlc Test in diagnosis and prognosis of diabetic patients. Biomark Insights 11: 95-104, 2016.

31. Monnier L and Colette C: Contributions of fasting and postprandial glucose to hemoglobin Alc. Endrocr Pract 12 (Suppl 1): 42-46, 2016.
32. Christakos S, Dhawan P, Porta A, Mady LJ and Seth T: Vitamin D and intestinal calcium absorption. Mol Cell Endocrinol 347: 25-29, 2011.

33. Papatheodorou K, Banach M, Bekiari E, Rizzo $M$ and Edmonds M: Complications of Diabetes 2017. J Diabetes Res 2018: 3086167, 2018. 